\title{
Symptoms Experienced by Patients with Carpal Tunnel Syndrome
}

\author{
Sanjoy K. Gupta and Timothy J. Benstead
}

\begin{abstract}
Background: Patients with carpal tunnel syndrome (CTS) sometimes report sensory symptoms outside the median nerve distribution. This study was designed to provide a more detailed assessment of these symptoms. Methods: Patients with clinical suspicion of upper limb neuromuscular lesions were divided into those with electrodiagnostic (EDX) evidence of CTS, and those without. CTS patients with superimposed nerve abnormalities were excluded. Motor and sensory symptoms were assessed in the exclusive CTS patients. Results: Over $50 \%$ of patients with exclusive CTS reported tingling or numbness over the whole hand, ulnar or radial nerve distributions. Some patients reported symptoms proximal to the wrist. Sensory signs did not extend beyond the median nerve distribution. Numbness and nocturnal pain were predictive of positive EDX evidence of CTS. Conclusions: Sensory symptoms outside the distribution of the median nerve are common in CTS. For enhanced sensitivity in diagnosis it is useful to be aware of these "atypical" symptoms. Reports of numbness and nocturnal pain are strong indicators of CTS.
\end{abstract}

RÉSUMÉ: Symptomatologie des patients qui ont un syndrome du tunnel carpien. Introduction: Les patients qui ont un syndrome du tunnel carpien (STC) rapportent parfois des symptômes sensitifs en dehors du territoire du nerf médian. Cette étude a été conçue pour fournir une évaluation plus détaillée de ces symptômes. Méthodes: Les patients chez qui on soupçonnait cliniquement des lésions neuromusculaires du membre supérieur ont été répartis en deux groupes selon qu'ils présentaient des signes électrodiagnostiques (EDX) de STC ou pas. Les patients porteurs d'un STC qui présentaient également des anomalies nerveuses ont été exclus. Les symptômes moteurs et sensitifs ont été évalués seulement chez les patients porteurs d'un STC. Résultats: Plus de $50 \%$ des patients qui n'avaient qu'un STC ont rapporté des picotements ou un engourdissement de toute la main, du territoire cubital ou radial. Certains patients ont rapporté des symptômes en amont du poignet. Les signes sensitifs ne dépassaient pas le territoire du nerf médian. L'engourdissement et la douleur nocturne étaient prédictifs d'un STC EDX positif. Conclusions: Les symptômes sensitifs hors du territoire du nerf médian sont fréquents dans le STC. Pour une plus grande sensibilité diagnostique, il est utile de connaître l'existence de ces symptômes "atypiques". Une histoire d'engourdissement et de douleur nocturne sont fortement en faveur d'un STC.

Can. J. Neurol. Sci. 1997; 24: 338-342

The usual symptomatic presentation of carpal tunnel syndrome (CTS) has been described in numerous large studies. ${ }^{1-3}$ The symptoms include pain, paresthesias, numbness and weakness. The pain often radiates to the median nerve sensory distribution of the thumb, index and middle finger, but pain radiating proximal to the wrist is frequently reported ${ }^{1,2}$ Numbness and tingling within the sensory distribution of the median nerve are also typical symptoms reported in the literature in patients with CTS. Sensory symptoms outside the classical distribution of the median nerve are often mentioned in studies and reviews of $\mathrm{CTS}^{1-5}$ but a detailed evaluation of these symptoms with an atypical distribution correlating to modern electrodiagnostic techniques is not available. A report of numbness beyond the sensory distribution of the median nerve may raise the concern of an additional nerve lesion, ${ }^{6}$ but the observation of many ${ }^{7}$ is that the symptoms of CTS alone can extend well beyond the distribution of the affected nerve.

This study was designed to obtain a clearer understanding of the scope of symptoms outside the median nerve distribution reported by patients with CTS.

\section{Materials ANd Methods}

\section{Patient Recruitment}

Patients referred for electrodiagnostic evaluation of upper limb neuromuscular lesions underwent testing using standard methods. Patients were included in the group with suspected CTS if they complained of tingling or numbness in a distribution including the hand, or had pain in a region including the wrist or hand, or had weakness in the median nerve distribution and did not have signs of a nerve lesion other than the median nerve. Patients were not excluded from this group if symptoms extended beyond the distribution of the median nerve as these

From the Division of Neurology, Dalhousie University, Halifax, Nova Scotia. RECEIVED JANUARY 16, 1997. ACCEPTED IN FINAL FORM APRIL 21, 1997.

This study was presented in part at the Canadian Congress of Neurological Sciences, London, Ontario, Canada. June 27, 1996.

Reprint requests to: Dr. Timothy J. Benstead, Division of Neurology, Dalhousie University, Queen Elizabeth II Health Sciences Centre, Halifax, Nova Scotia, Canada B3H 2 Y9 
patients may have had atypical CTS symptoms. Patients referred for evaluation of upper limb neuromuscular lesions other than CTS were included in the study to provide a comparison group for the CTS patients. Patients underwent standard protocols described below to determine whether: 1) Electrodiagnostic (EDX) criteria for CTS were met; 2) EDX criteria for other neuromuscular disorders were present that might produce symptoms in the affected limb.

\section{Questionnaire Design}

All patients were asked to complete a questionnaire. Information was obtained about the quality and distribution of sensory and motor symptoms (viz; numbness, tingling, pain, and weakness) and presence of nocturnal pain. Participants were asked to sketch the areas of their upper limb that were affected with abnormal sensation (numbness and tingling), weakness or pain. Epidemiological data was obtained regarding age and occupation of patients. All patients participated in the study with informed consent. The questionnaire and consent form were approved by the institution's Research Review Committee prior to commencement of the study.

\section{EDX Studies}

Standard nerve conduction techniques were used using surface stimulation and recording electrodes. ${ }^{8}$ Standard practice recommendations established by the American Association of Electrodiagnostic Medicine for evaluation of CTS were followed. ${ }^{9}$ If antidromic sensory conduction results stimulating the median nerve over the wrist and recording over index finger were normal, the orthodromic palmar stimulation technique was used comparing median and ulnar distal latency over an $8 \mathrm{~cm}$ distance across the wrist.$^{10} \mathrm{~A}$ median to ulnar palmar distal latency difference greater than $0.3 \mathrm{~ms}$ was taken as evidence of CTS.

\section{Search Algorithms}

Using a commercially available software package (File Maker ${ }^{\mathrm{TM}}$ Pro, Claris Corporation, Santa Clara, CA), a database was established with data from completed questionnaires and EDX records. Database search algorithms were designed based on standard protocols used to determine whether EDX criteria for CTS were met (criteria set 1) (Table 1).

Criteria set 2 was used to exclude patient records that showed EDX criteria possibly indicative of a diffuse neuropathy or proximal median neuropathy. It was judged that if a patient had a diffuse neuropathy, it may be reflected by a slowing of median motor or sensory nerve conduction velocity (NCV) beyond the mild slowing sometimes seen in CTS. "In the current study, patients were only included in the CTS group if median motor and sensory NCV were not slowed more than $10 \%$ of the lower limit of normal (i.e., motor NVC $>43 \mathrm{~m} / \mathrm{s}$ and forearm sensory $\mathrm{NCV}>49 \mathrm{~m} / \mathrm{s}$ ).

Criteria set 3 excluded patient records with ulnar nerve or more diffuse conduction abnormalities.

Criteria set 4 excluded patients with other upper limb focal nerve lesions. Any patient being evaluated for possible CTS

Table 1: EDX Criteria for Confirmation of Clinically Suspected CTS, Exclusion of Diffuse Neuropathy, Ulnar Nerve Abnormalities and Other Focal Nerve Lesions.

\begin{tabular}{|c|c|c|c|}
\hline $\begin{array}{l}\text { Criteria set 1: Diagnosis } \\
\text { of CTS }\end{array}$ & $\begin{array}{l}\text { Criteria set 2: To rule out } \\
\text { diffuse neuropathy }\end{array}$ & $\begin{array}{l}\text { Criteria set 3: To rule out } \\
\text { ulnar nerve abnormalities }\end{array}$ & $\begin{array}{l}\text { Criteria set 4: To rule out } \\
\text { other focal nerve lesions }\end{array}$ \\
\hline $\begin{array}{l}\text { Median motor } \\
\text { distal latency }>4.5 \mathrm{~ms} \\
\quad \text { OR } \\
\text { Median sensory } \\
\text { (antidromic) }^{\dagger} \\
\text { distal latency }>3.6 \mathrm{~ms} \\
\quad \text { OR } \\
\text { Median palmar } \\
\text { distal latency }>2.3 \mathrm{~ms} \\
\text { OR } \\
\text { Palmar median-ulnar } \\
\text { distal latency difference } \\
>0.3 \mathrm{~ms}\end{array}$ & $\begin{array}{l}\text { Median motor }{ }^{*} \\
\text { conduction velocity } \\
>43 \mathrm{~m} / \mathrm{s} \\
\quad \text { AND } \\
\text { Median forearm sensory } \\
\text { (antidromic) }^{\dagger} \\
\text { conduction velocity } \\
>49 \mathrm{~m} / \mathrm{s}\end{array}$ & $\begin{array}{l}\text { Ulnar motor } \\
\text { distal latency }<3.6 \mathrm{~ms} \\
\quad \text { AND } \\
\text { Ulnar sensory (antidromic) } \\
\text { distal latency }<3.1 \mathrm{~ms} \\
\quad \text { AND } \\
\text { Ulnar motor }{ }^{\ddagger} \text { conduction } \\
\text { velocity }>51 \mathrm{~m} / \mathrm{s} \\
\quad \text { AND } \\
\text { Ulnar sensory (antidromic) } \\
\text { conduction velocity }>55 \mathrm{~m} / \mathrm{s} \\
\quad \text { AND } \\
\text { Ulnar amplitude difference } \\
\text { across elbow }<25 \% \\
\quad \text { AND } \\
\text { Ulnar conduction velocity } \\
\text { difference across elbow }<10 \mathrm{~m} / \mathrm{s} \\
\quad \text { AND } \\
\text { Ulnar motor amplitude }>6 \mathrm{mV} \\
\quad \text { AND } \\
\text { Ulnar sensory amplitude }>10 \mu \mathrm{V}\end{array}$ & $\begin{array}{l}\text { Normal needle EMG } \\
\text { outside thenar eminence } \\
\quad \text { AND } \\
\text { Normal radial sensory } \\
\text { nerve conduction }\end{array}$ \\
\hline $\begin{array}{l}\text { No. of patients meeting } \\
\text { criteria set } 1: 50 / 73\end{array}$ & $\begin{array}{l}\text { No. of patients meeting } \\
\text { criteria sets } 1 \& 2: 45 / 73\end{array}$ & $\begin{array}{l}\text { No. of patients meeting } \\
\text { criteria sets } 1,2 \& 3: 37 / 73\end{array}$ & $\begin{array}{l}\text { No. of patients meeting } \\
\text { criteria sets } 1,2,3 \& 4 \text { : } \\
37 / 73 \text { (ECTS) }\end{array}$ \\
\hline
\end{tabular}

Recording sites: "abductor pollicus brevis, index finger, "thypothenar eminence, ${ }^{\S}$ fifth digit. 
where cervical radiculopathy or brachial plexus lesion was considered as an additional diagnostic possibility underwent screening needle electromyography. Patients with cervical pain, proximal upper extremity pain, cervical dermatomal sensory symptoms or signs, upper extremity reflex loss or weakness outside the distribution of the median hand muscles underwent needle electromyography of representative muscles of cervical nerve roots. No patients were included in the ECTS group if imaging studies demonstrated a cervical disc protrusion, cervical stenosis or if the clinical evaluation provided a strong suspicion of radiculopathy. Patients with symptoms in the radial nerve distribution underwent radial nerve conduction studies and needle electromyography of appropriate radial muscles.

Patient records that met criteria sets $1,2,3$, and 4 thus showed EDX evidence of CTS in the absence of other above described abnormalities, and were labeled "Exclusively CTS" (ECTS) records. Patient records that did not meet criteria set 1 were labeled non-CTS records.

\section{Results}

\section{Subject Data}

One hundred and six (106) consecutive patients referred to the EMG lab with clinical suspicion of an upper limb neuromuscular disorder were asked to participate in the study and 105 agreed. Patients were not excluded from the study due to a known cause of diffuse neuropathy such as diabetes. Only a few patients fell into this category and none were found to have ECTS. Of the 105 participants, 73 patients had clinically suspected CTS (Table 2). These included patients clinically felt to have typical CTS symptoms and atypical CTS symptoms (i.e., sensory distribution of symptoms included areas outside the median nerve distribution). The remaining 32 patients were referred for evaluation of possible ulnar neuropathy (11), cervical radiculopathy (8), diffuse neuropathies (5), radial neuropathy (1), thoracic outlet syndrome (1) or other abnormalities (6). On examination of the patients' EDX records, 50 patients fulfilled criteria set 1 . These patients had all been referred for possible CTS. Only 37 patients met criteria sets $1,2,3$ and 4 to be classified ECTS patients, 10 of these were male (mean age 40.9) and 27 were female (mean age 48.0). Thirteen patients had EDX evidence of CTS (met criteria set 1) but also EDX evidence of

Table 2: Patients with EDX criteria for CTS.

Total patients

Patients with clinical

suspicion of CTS

Patients with EDX

criteria for CTS

Patients with EDX

criteria for CTS and no

other nerve lesion

(ECTS group)

Patients without EDX criteria

for CTS (non-CTS group) an additional nerve lesion (i.e., failed criteria sets 2, 3, or 4). These patients were excluded from analysis. This group consisted of 7 patients with an additional ulnar lesion and 6 with diffuse neuropathy based on the EDX criteria previously outlined. The 55 non-CTS patients used as a comparison group consisted of patients with normal EDX (44), ulnar lesions (6), cervical radiculopathy (3), radial neuropathy (1) and diffuse neuropathy (1).

\section{Symptoms in CTS Patients}

The primary objective of this study was to delineate the distribution of symptoms in a group of patients with electrodiagnostic criteria solely for CTS. For analysis of symptoms, the ECTS group (37 patients) was further subdivided into those patients with bilateral CTS (15 patients) and those with unilateral CTS (22 patients). Each affected arm (52 total) was then treated as a independent sample.

Numbness, tingling and weakness were common symptoms for both ECTS and non-CTS patients (Table 3). Of these 3 symptoms only numbness was significantly different between the 2 groups $\left(\chi^{2}=6.8, p<0.01\right)$. A query for numbness would in the current groups produce a positive Likelihood Ratio (LR) of 3.0 for CTS (sensitivity $=92 \%$, specificity $=31 \%$ ).

A large number of ECTS patients reported either numbness, tingling, weakness or pain in the arm proximal to the wrist. Only a total of $39 \%(20 / 52)$ and $50 \%(25 / 52)$ of affected arms were clearly reported to be numb and tingle solely within the hand and wrist respectively. Pain was reported up to the forearm in $21 \%(11 / 52)$ of affected arms and up to the shoulder in $8 \%$ $(4 / 52)$. Weakness was reported proximal to the wrist in $21 \%$ (11/52).

In the ECTS group, detailed analysis of the distribution of sensory symptoms in the hands revealed that $33 \%$ of the affected hands were reported to tingle or be numb in an exclusively median distribution (Table 4 ). A small percentage (4\%) described a clear ulnar distribution of tingling/numbness. The most frequent complaint $(40 \%)$ was abnormal sensation in the whole hand. This finding was significant as the ECTS group of patients were electrodiagnostically shown to have solely median nerve dysfunction, with no objective evidence of ulnar nerve abnormality or diffuse neuropathy. These patients did not have examination features of sensory loss or weakness outside the distal median distribution, despite the report of symptoms.

Pain was a common symptom in patients with ECTS and the non-CTS group (Table 3). Patients chose the best description of the daytime/night-time pattern of their pain. Nocturnal pain was a sensitive indicator of CTS, as $84 \%$ of the patients in the ECTS group reported night-time occurrence of pain. Only night-time pain was highly indicative of ECTS $\left(\chi^{2}=6.5, \mathrm{p}<0.01\right)$. There were no patients in the ECTS group that chose a sole daytime occurrence of pain. This contrasts with the non-CTS patient group where $18 \%$ reported only daytime presentation of pain $\left(\chi^{2}=7.55, \pi<0.01\right)$. If nocturnal pain was used as a diagnostic tool for CTS in our group of patients, then such a query would have a positive likelihood ratio (LR) of 2.5 (sensitivity $=84 \%$, specificity $=33 \%$ ).

Participants were also asked whether the onset of pain was related to activity. As can be seen in Table 3, there were no significant differences in the responses of the ECTS and the nonCTS group, although a lower percentage of ECTS patients correlated the onset of pain to use of the arm. 
Table 3: Common Symptoms in Exclusively CTS (ECTS) vs. Non-CTS Patients.

\begin{tabular}{|c|c|c|c|}
\hline Symptoms & ECTS & Non-CTS & $x^{2}$ \\
\hline Numbness & $34 / 37(92 \%)$ & $38 / 55(69 \%)$ & $6.80(\mathrm{p}<0.01)$ \\
\hline Tingling & $30 / 37(81 \%)$ & $44 / 55(80 \%)$ & 0.02 \\
\hline Weakness & $28 / 37(76 \%)$ & $45 / 55(82 \%)$ & 0.51 \\
\hline Pain at anytime & $31 / 37(84 \%)$ & $47 / 55(85 \%)$ & 0.05 \\
\hline Only daytime pain & $0 / 37 \quad(0 \%)$ & $10 / 55(18 \%)$ & $7.55(\mathrm{p}<0.01)$ \\
\hline Only night-time pain & $12 / 37(33 \%)$ & $6 / 55(11 \%)$ & $6.51(\mathrm{p}<0.01)$ \\
\hline Pain both day and night & $19 / 37(51 \%)$ & $31 / 55(56 \%)$ & 0.22 \\
\hline Pain when arms are in use & $4 / 37(13 \%)$ & $12 / 55(22 \%)$ & 1.87 \\
\hline Pain when arms are at rest & $10 / 37(32 \%)$ & $10 / 55(18 \%)$ & 1.02 \\
\hline Pain during use and at rest & $12 / 37(39 \%)$ & $24 / 55(44 \%)$ & 1.17 \\
\hline No pain & $6 / 37(16 \%)$ & $7 / 55(12 \%)$ & 0.22 \\
\hline
\end{tabular}

\section{Discussion}

We have assessed the distribution of motor and sensory symptoms in a group of patients with suspected CTS, who meet EDX criteria for CTS and have no other significant nerve dysfunction as determined by EDX and clinical examination. Our findings confirm the observation that many CTS patients present with sensory symptoms outside the median nerve distribution of the hand. In our experience, these patients are often referred to the electrodiagnostic laboratory with a working diagnosis of "atypical" CTS in an attempt to account for the seemingly illogical sensory manifestations.

A patient with "atypical" CTS referred for electrodiagnostic tests, might be evaluated keeping the following possibilities in mind: i) The patient may not have CTS. The patient has either a more diffuse peripheral neuropathy or a more proximal injury to the brachial plexus or cervical nerve roots has led to the symptoms; ii) The patient may have superimposed ulnar nerve abnormalities that confound the issue; iii) The patient may have an anomalous sensory distribution of the median nerve; iv) The patient may have CTS, and the symptoms outside the median distribution reflect

Table 4: Distribution of Numbness and Tingling in the 52 Affected Hands of 37 Exclusively CTS (ECTS) Patients.

\begin{tabular}{lc}
\hline Distribution of Numbness or Tingling & No. of Affected Arms \\
\hline Median distribution & $17 / 52(33 \%)$ \\
Ulnar distribution & $2 / 52(4 \%)$ \\
Whole hand & $21 / 52(40 \%)$ \\
Radial distribution & $8 / 52(15 \%)$ \\
No tingling/numbness & $4 / 52(8 \%)$ \\
\hline
\end{tabular}

abnormal/compensatory feedback from the other sensory dermatomes and interpretation of these sensations by the patient. Alternatively, the peripheral nerve lesion may induce remodeling of central pathways.

Careful evaluation correlating EDX with clinical findings is necessary to rule out the first two possibilities. The third possibility is rare, but has been reported. ${ }^{12}$ The fourth group of possibilities are speculative and cannot be answered with the current study design. The present study was designed to evaluate symptoms in patients with CTS and no other detectable nerve lesion.

The results of the current study suggest that reports of nonmedian nerve distribution of sensory symptoms are common in the CTS patient population. Almost $60 \%$ of the patients with exclusive EDX criteria for CTS (the ECTS group) reported numbness or tingling paresthesias over the whole hand or in ulnar or radial nerve distributions. Most often the sensory symptoms include, but may extend beyond the median distribution of the hand. A recent report outlined the finding of sole ulnar distribution sensory symptoms in CTS patients. ${ }^{13}$ In our study solely ulnar distribution symptoms occurred $4 \%$ of the time. Although exclusive median distribution sensory symptoms in the hand were reported by one-third of patients, the commonest report was of whole hand numbness and tingling. Moreover, symptoms of tingling, numbness and pain were not restricted to the hand alone, but were reported proximal to the site of the putative lesion, in the arm.

Nerve conduction studies will not always confirm the diagnosis of CTS in patients clinically felt to have the disorder. Clinical correlation is an essential aspect of interpretation of the EDX data. By using very strict EDX criteria in the present study for confirmation of CTS, we did exclude some patients with CTS diagnosed only by clinical criteria from the analysis of symptoms in the ECTS group. The exclusion of these patients was important to provide maximum confidence in the correct diagnosis of CTS. This exclusion does not alter the 
conclusion that many patients with CTS have symptoms outside the typical median nerve distribution.

Our findings support previous reports that the timing of symptoms and some characteristics of the symptoms are useful clinical indicators of CTS. ${ }^{1,2}$ In the current study, a patient report of numbness combined with nocturnal pain provided a high likelihood that the patient had CTS and not some other neuromuscular lesion of the upper limb. Requiring EDX confirmation of CTS before including the patient in the CTS group means the high likelihood ratios for nocturnal pain and numbness were derived from the patient group where this diagnosis was most certain. These two indicators certainly are predictive of patients who will have electrodiagnostic confirmation of CTS.

This study of CTS is a rigorous evaluation of sensory symptoms within and outside the typical median distribution with correlative EDX evaluation to exclude other neuromuscular lesions in the upper limb. This approach has provided a clearer description of the symptoms with confidence that these can arise solely from compression of the median nerve at the carpal tunnel. With the increasing prevalence of CTS, ${ }^{14,15}$ it is imperative that the clinical community enhance awareness of all patterns of presentation of CTS. We confirm that reports of nocturnal pain and numbness should be important day-to-day adjuncts for the clinical assessment of this common disorder.

\section{ACKNOWLEDGEMENTS}

The authors thank the patients who enthusiastically participated in this study, Drs. R.A. Purdy, V. Bhan, and L.P. Heffernan for electrodiagnostic data on patients, as well as Mary Yochoff, Bruce Goddard, Pearl Berriman and Susan Rahey for helpful discussions. This work was supported by a studentship (UIMRF and Faculty of Medicine Research Committee Studentship, Dalhousie University).

\section{REFERENCES}

1. Stevens JC, Sun S, Beard CM, O'Fallon WM, Kurland LT. Carpal tunnel syndrome in Rochester, Minnesota, 1961 to 1980. Neurology 1988; 38: 134-138.

2. Phalen GS. The carpal-tunnel syndrome: seventeen years' experience in diagnosis and treatment of six hundred fifty-four hands. J Bone Joint Surg 1966; 48: 211-228.

3. Katz JN, Larson MG, Sabra A, et al. The carpal tunnel syndrome: diagnostic utility of the history and physical examination findings. Ann Int Med 1990; 112: 321-327.

4. Stewart JD. The median nerve. In: Focal Peripheral Neuropathies. New York: Raven Press, 1993: 170-185.

5. Ross MA, Kimura J. AAEM case report \#2: the carpal tunnel syndrome. Muscle Nerve 1995; 18: 567-573.

6. Spinner, RJ, Bachman, JW, Amadio, PC. The many faces of carpal tunnel syndrome. Mayo Clin Proc 1989; 64: 829-836.

7. Bohr T. Carpal tunnel syndrome. (Letter)Mayo Clin Proc 1990; 65: 122-125.

8. Daube JR. Nerve conduction studies. In: Aminoff MJ, ed. Electrodiagnosis in Clinical Neurology. New York: Churchill Livingston, 1986: 265-306.

9. American Association of Electrodiagnostic Medicine. Practice parameter for electrodiagnostic studies in carpal tunnel syndrome: summary statement. Muscle Nerve 1993; 16: 1390-1391.

10. Daube JR. Percutaneous palmar median nerve stimulation for carpal tunnel syndrome. Electroencephalogr Clin Neurophysiol 1977; 43: 139-140.

11. Hansson S. Does forearm mixed nerve conduction velocity reflect retrograde changes in carpal tunnel syndrome? Muscle Nerve 1994; 17: 725-729.

12. Pecina MM, Krmpotic-Nemanic J, Markiewitz J. Carpal Tunnel Syndromes. Boca Raton, CRC Press, Inc., 1991: 55-67.

13. Oswald TA, Wertsch JJ, Vennix MJ, Brooks LL, Spreitzer AM Ulnar paresthesias as a presenting symptom of carpal tunnel "syndrome". Muscle Nerve 1994; 17: 1082.

14. Morgenstern H, Kelsh M, Kraus J, Margolis W. A cross-sectional study of hand/wrist symptoms in female grocery checkers. Am J Ind Med 1991; 20: 209-218.

15. MMWR. Occupational disease surveillance: carpal tunnel syndrome. Morb Mortal Wkly Rep 1989; 38: 485-489. 